原著

\title{
動注蛍光脳血管撮影による脳表血流評価
}

一インドシアニン・グリーンとフルオレセインの 3 症例における比較検討一

\author{
鈴木 恭一, 市川剛, 渡部 洋一
}

\section{Evaluation of Cortical Blood Flow by Intra-arterial Fluorescence Cerebral Angiography: Comparison Between Indocyanine-green and Fluorescein in Three Cases}

\author{
Kyouichi Suzuki, M.D., Tsuyoshi Ichikawa, M.D., and Yoichi Watanabe, M.D. \\ Department of Neurosurgery, Fukushima Red Cross Hospital, Fukushima, Japan
}

\begin{abstract}
Summary: We evaluated the usefulness of intra-arterial fluorescence cerebral angiography (FCAG) from a catheter inserted into the external carotid artery (ECA) via the superficial temporal artery (STA) for detecting the blood flow in the small arteries, capillaries and small veins in the brain surface during neurological surgery. After indocyanine green (ICG) or fluorescein sodium (Fluorescein) was injected into the STA, fluorescein reached the intracranial internal carotid artery (ICA) through the common carotid artery or anastomoses between the ECA and ICA. Fluorescence in the vessels of brain surface was observed through a microscope and recorded on DVD image.

In large arteries such as internal cerebral artery, images by FCAG using ICG were clearer than these by fluorescein-FCAG. On the other hand, in small arteries, capillaries and small veins in the brain surface, fluorescein-FCAG was superior to ICG-FCAG in resolution.

Intra-arterial fluorescein-FCAG is very promising for estimation of the blood flow in the brain surface because it allows confirmation of delay and stagnation of capillary arterial blood flow on the brain surface. Based on our findings, we suggest that observation of the blood flow on the brain surface by fluorescein-FCAG is useful to prevent unexpected cerebral infarctions and to improve the surgical outcome.
\end{abstract}

\author{
Key words: \\ - fluorescence angiography \\ - fluorescein sodium \\ $\cdot$ indocyanine green \\ - intraoperative monitoring \\ $\cdot$ aneurysm surgery
}

Surg Cereb Stroke (Jpn) 42: 207-213, 2014

\section{はじめに}

狭窄や閉塞をきたした脳主幹動脈の末梢灌流領域に側副 血行路が発達しているのか, あるいは脳静脈の遮断により 静脈灌流障害が生じるのかなど, 術中に脳表の細動脈や毛 細血管, 細静脈の血流評価が求められる場面は少なくな
い. 今回, 脳表の細動脈から毛細血管, 細静脈の血流を評 価する手段としての, 動注蛍光脳血管撮影(intra-arterial fluorescence cerebral angiography: 動注 FCAG)の有用 性を検討した。 また, 現在臨床使用されているインドシア ニン・グリーンとフルオレセインを同一症例で使用し, 両 色素の特徴に関しても検討した。 


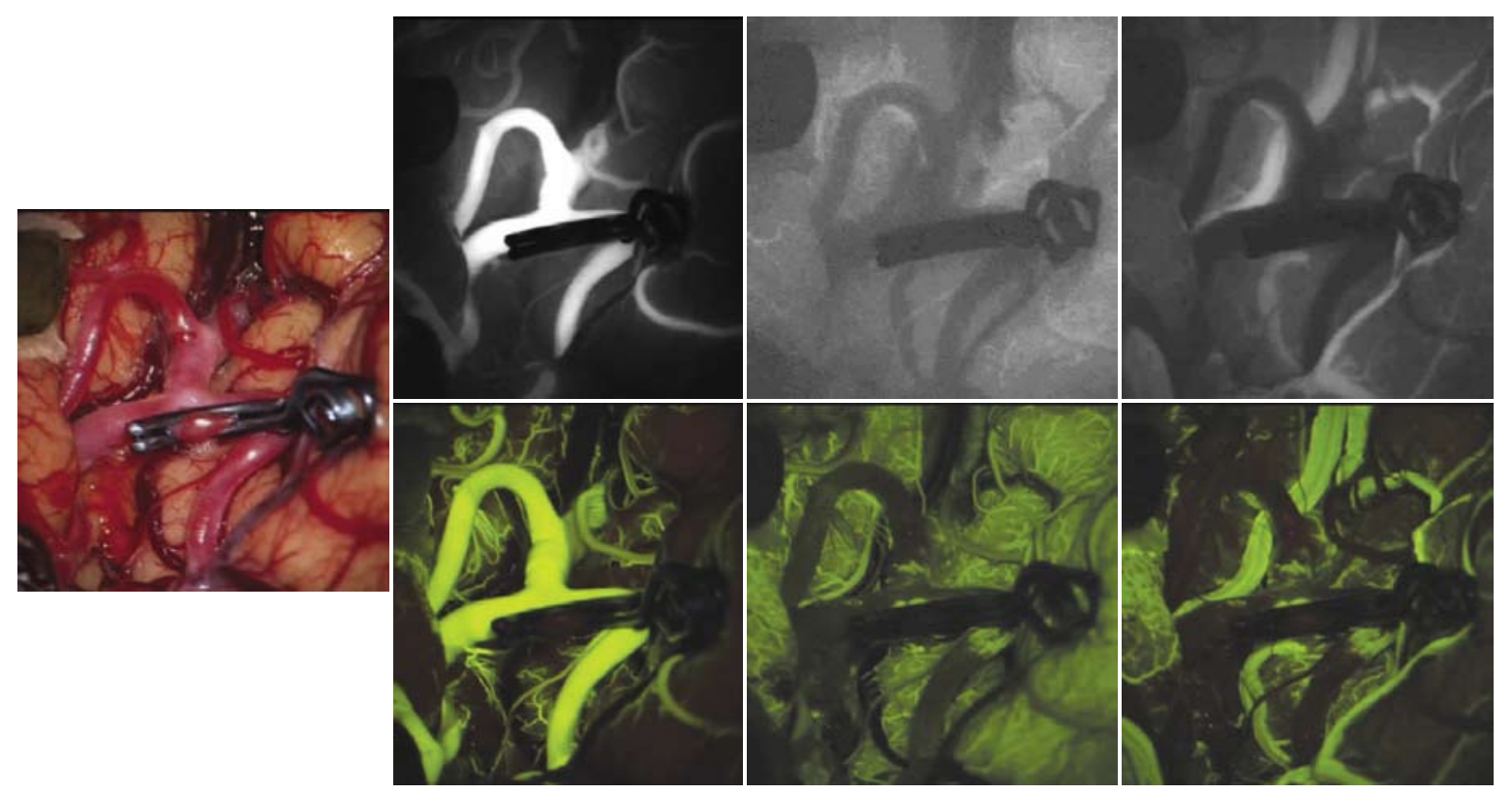

Fig. 1 Intraoperative photographs and fluorescence angiograms of the illustrative case 1. Regular microscopic view (A), intra-arterial angiography using indocyanine green at arterial phase $(\mathbf{B})$, capillary phase $(\mathbf{C})$, and venous phase $(\mathbf{D})$ and intra-arterial angiography using fluorescein sodium at arterial phase $(\mathbf{E})$, capillary phase $(\mathbf{F})$, and venous phase (G) are shown. Bright fluorescence emission with quick clearance was observed in intra-arterial FCAG. Fluorescence emission from the cerebral arteries, capillaries, and veins could be independently evaluated by ICG-FCAG and fluorescein-FCAG. In large arteries such as M1 segment of middle cerebral artery, images by FCAG using ICG were clearer than these by fluorescein-FCAG. On the other hand, in small artery, capillary and small vein in the brain surface, fluorescein-FCAG was superior to ICG-FCAG in resolution.

$F C A G=$ fluorescence cerebral angiography, fluorescein=fluorescein sodium, $\quad I C G=$ indocyanine green

\section{対象および方法}

脳動脈瘤クリッピング術を施行した中大脳動脈瘤の 3 症 例を対象とした. インドシアニン・グリーンを用いた蛍光 脳血管撮影(ICG-FCAG) では, OPMI ${ }^{\circledR}$ Pentero $^{\circledR}$ (Carl Zeiss, Oberkochen, Germany)を使用した. フルオレセイ ンを用いた蛍光脳血管撮影(fluorescein-FCAG) は, M500OHS-1 (Leica, Wetzlar, Germany)に hyper LED 光 源 (PFB2-20SW-F-JT, CCS, 京都) から照射される青色光 を引き入れて術野を照射し, 観察光軸上に設置した透過領 域点 $550 \mathrm{~nm}$, カット領域点 $450 \mathrm{~nm}$ の long pass filter (サ イメンデザイン, 東京)を透して観察した.

蛍光色素の動注ルートとして, あらかじめ皮弁の切開縁 で確保した浅側頭動脈の断端から $3 \mathrm{~F}$ の peripherally inserted central catheter (PICC: Argyle ${ }^{\mathrm{TM}}$, Covidien, Japan）を 5-10 cm 挿入し, 内腔をへパリン加生食で満た しておいた.

クリッピング術後に, 100 倍に希釈したインドシアニ
ン・グリーン(ジアグノグリーン®，第一三共) $5 \mathrm{ml}$ PICC を介して外頚動脈内に投与した. 外澒動脈と内頝動 脈間の anastomosis や総䅡動脈分岐部を経由して内頝動脈 内へ流れ込む蛍光をビデオに記録した．引き続き同一術野 で, 10 倍に希釈したフルオレセイン(フルオレサイト静注 $500 \mathrm{mg}^{\circledR}$, 日本アルコン) $5 \mathrm{ml}$ を注入し, 脳血管内を流れ る蛍光を術者が顕微鏡を通して直接観察するとともに DVDに記録した.

FCAG 施行後ただちに, FCAGの映像をパーソナルコ ンピューターにAVI ファイルとして取り込み, 画面上で 脳動脈, 脳表, 脳静脈それぞれにROIを設置し, それぞ れの ROI における蛍光輝度の推移を, 映像輝度解析ソフ トROIs (IMI, 仙台)を用いてグラフ化した.

FCAG を施行するにあたり，すべての患者またはその 家族から informed consentを得た。

$$
\text { 結果 }
$$

皮膚切開部で確保した浅側頭動脈頭頂枝の断端から $3 \mathrm{~F}$ 

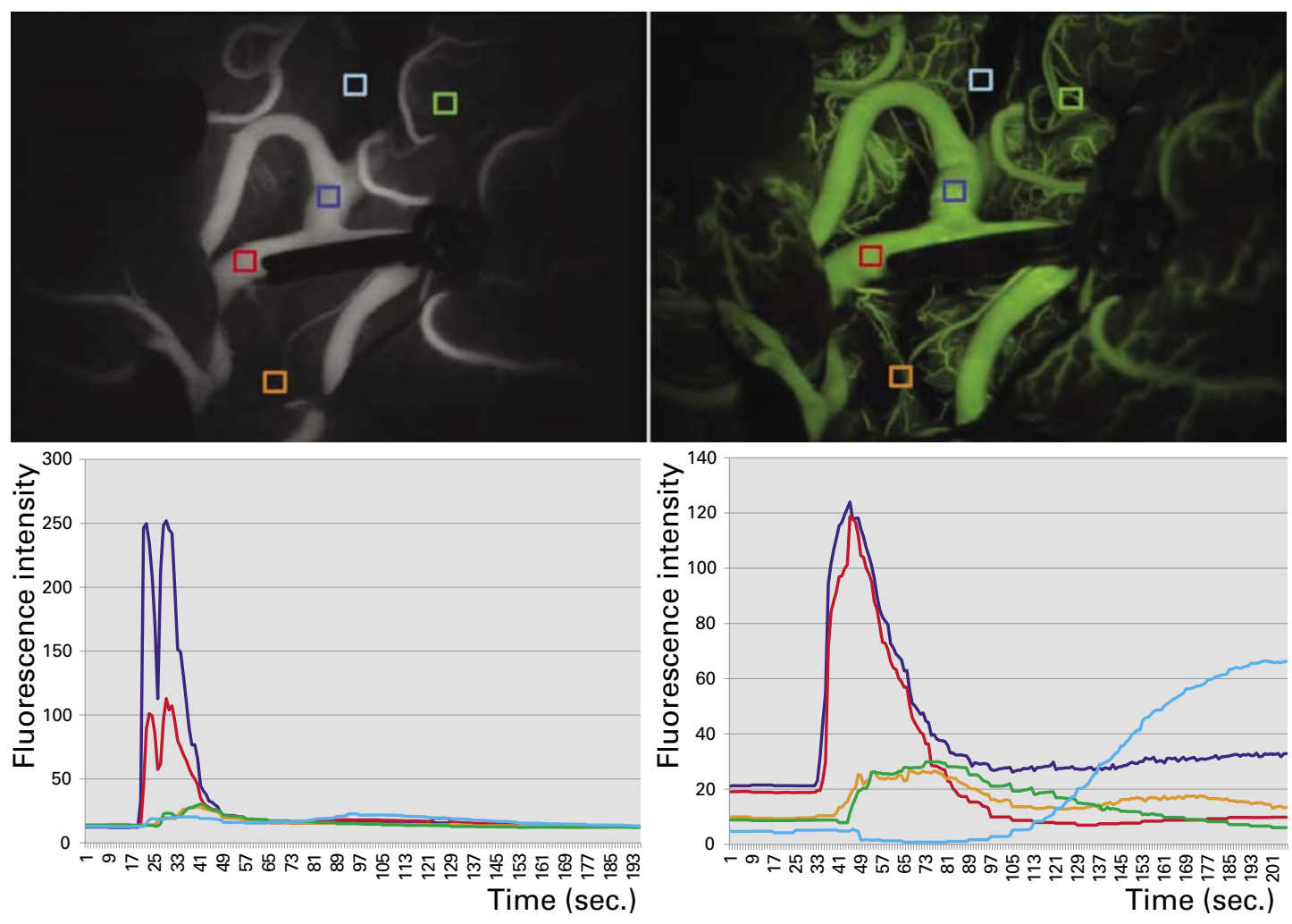

Fig. 2 Intraoperative ICG and fluorescein fluorescence angiograms and changes in fluorescence intensity at various ROls in the illustrative case 1.

ROls were set at the M1 segment of the MCA (blue open square), the M2 segment (red open square), the frontal lobe (green open square), the temporal lobe (orange open square) and the vein (light blue open square), and changes in fluorescence intensity at each ROls were plotted. Graph of fluorescence intensity changes of fluorescein FCAG showed a sharp peak first in the artery, followed by independent peaks at the brain surface and in the vein because of the quick clearance of fluorescence by intra-arterial injection. ICG-FCAG showed sharp peak in the arterial phase but show low peaks in capillary and venous phase.

の PICC カテーテルを挿入する手技に要する時間は 10 分 程度であった．カテーテルが外䅡動脈本幹に向かわずに浅 側頭動脈前頭枝に迷入した症例が 1 例あり，頭頂枝に引き 戻したのち用手的にカテーテルを浅側頭動脈本幹へ誘導し た. 5-10 cm 挿入したカテーテル先端は, 浅側頭動脈の頓 骨弓付近に達していた.

PICC カテーテルから ICG および fluorescein を動脈内 投与すると, 数秒後に動脈, 毛細血管, 静脈と順次蛍光が 観察された。脳表の径 $0.5 \mathrm{~mm}$ 以上の血管は, ICG-FCAG と fluorescein-FCAGいずれにおいても蛍光を確認できた が, fluorescein-FCAGにおいて蛍光輝度が強かった. 径 $0.1 \mathrm{~mm}$ 程度の血管は fluorescein-FCAG で描出されたもの の ICG-FCAGでは描出が困難であった。 また, 脳表の静 脈でも fluorescein-FCAGの方が観察される蛍光輝度が高 かった。なお脳深部を走行する内䅡動脈や中大脳動脈など 壁の厚い動脈では, ICG-FCAG が fluorescein-FCAGより
も血管内の血流を明瞭に描出した.

画像輝度解析は蛍光撮影終了後ただちに手術室内で施行 したが, 映像取り込みから解析までおよそ 5 分程度の時間 を要した. ICG-FCAGでは動脈上に設定した ROI から輝 度がきわめて高いピークが形成されたが，毛細血管や静脈 のピークは不明暸であり, 血流の評価が困難であった. fluorescein-FCAGでは, 毛細血管, 静脈それぞれが分離 されたピークとして描かれ，血流評価が可能であった。

〈症例 1〉70歳, 女性. 未破裂左中大脳動脈瘤ネックク リッピング後(Fig. 1A), まずICG-FCAGを施行した. ICG を動注すると数秒後には動脈から明瞭な蛍光が観察さ れた(Fig. 1B). 動脈からの蛍光が短時間で消退したのち に毛細血管が描出されたが, その蛍光は微弱であり毛細血 管を個別に判別することは困難であった(Fig. 1C). 毛細 血管の蛍光が消退したのちに静脈からの蛍光が観察された (Fig. 1D). 次に fluorescein-FCAG を施行し, 動脈, 毛細 


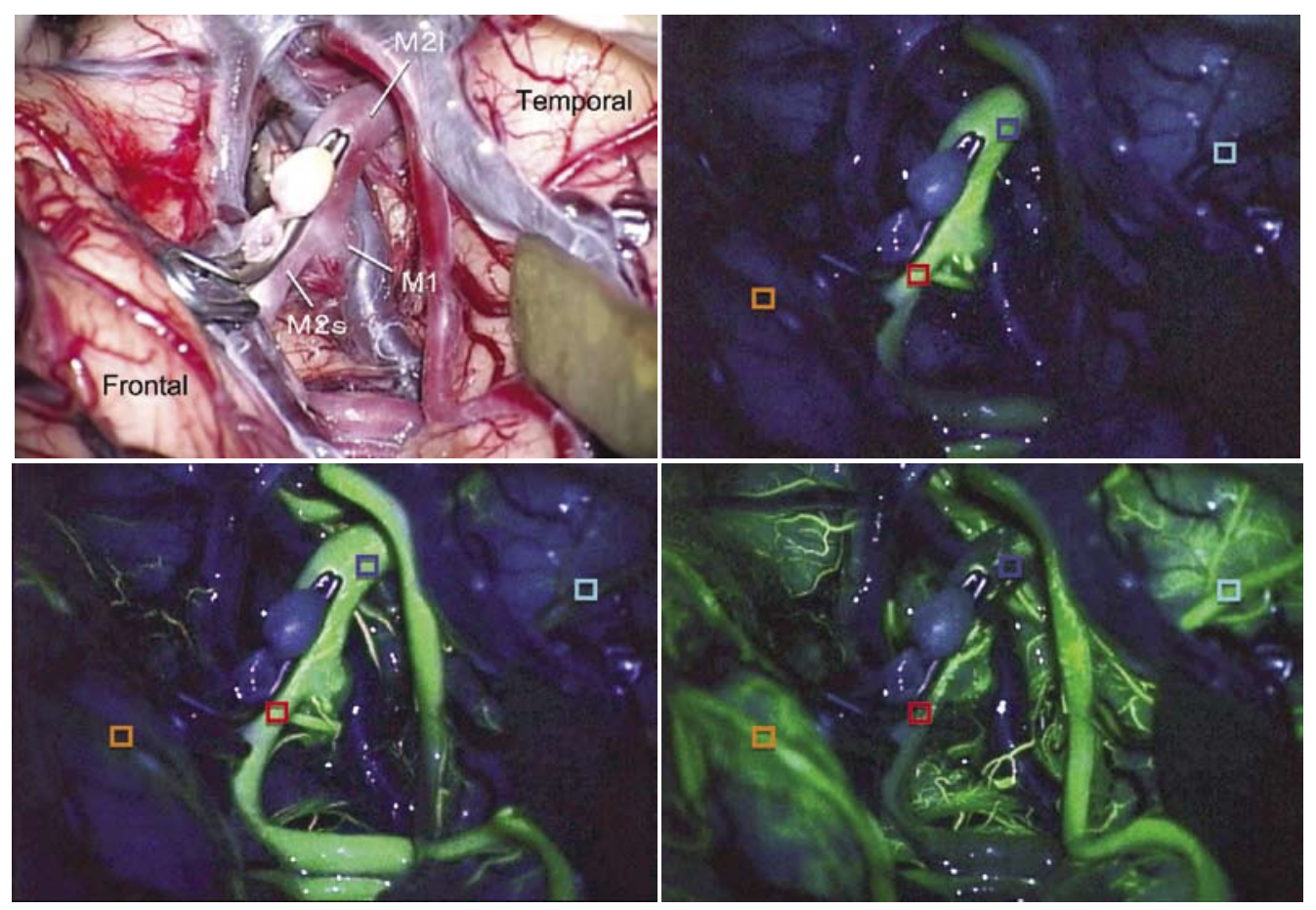

Fig. 3 Intraoperative photographs and fluorescence angiograms of the illustrative case 2. Regular microscopic view (A), intra-arterial fluorescein-FCAG at arterial phase (B), capillary phase $(\mathbf{C})$, and venous phase $(\mathbf{D})$ are shown. Bright fluorescence emission with quick clearance was observed during the arterial, capillary, and venous phase, and the blood flow delay of superior trunk of M2 was suspected. $\mathrm{M} 2=\mathrm{M} 2$ segment of middle cerebral artery

血管, 静脈からの蛍光を順追って確認した (Fig. 1E，F，G). 毛細血管と静脈からの蛍光は ICG-FCAG に比較してょり 明瞭に観察しえた。次に, ICG-FCAG と fluoresceinFCAG 両方の映像上で, 動脈, 脳表, 静脈に ROI を設定 し輝度解析を施行した (Fig. 2). ICG-FCAGでは, 動脈上 に設定した ROI から輝度がきわめて高いピークが形成さ れたが，毛細血管や静脈のピークは不明瞭であった，fluorescein-FCAGでは, ICG-FCAG に比較して動脈のピーク が低いものの, 毛細血管, 静脈それぞれが分離されたピー クを形成した。

〈症例 2〉 54 歳, 男性. 未破裂右中大脳動脈瘤. 動脈瘤 の薄い壁が右中大脳動脈側にも及んでおり，この部を含め てクリッピングした(Fig. 3A). 中大脳動脈 frontal branch に軽度の狭窄をきたしたことを顕微鏡下にも観察 し, fluorescein-FCAGでは, 狭窄部位で蛍光が出現する タイミングの遅延がみられた(Fig. 3B)。狭窄部位より末 梢の動脈からは明瞭な蛍光が観察され(Fig. 3C), 前頭葉 と側頭葉との比較において, 蛍光出現のタイミングや輝度 に明らかな差は認めなかった(Fig. 3D). 輝度解析では (Fig. 4), 中大脳動脈前頭枝の狭窄をきたした部位で蛍光出現 の遅延と輝度低下がみられたが, 脳表の細動脈では前頭葉
と側頭葉とで解析波形に差はみられなかった，中大脳動脈 前頭枝の狭窄が軽度であり, 脳表レベルでの血流低下が明 らかでなく，また同時に施行していた運動誘発電位にも変 化がないことを確認してクリッピング操作を終了した.

\section{考察}

脳主幹動脈を閉塞した際に側副血行路を介した血流が期 待できるのか, 脳動脈瘤クリッピングで親動脈に狭窄が生 じた際に灌流域の血流がどれほど低下しているのか，ある いは静脈遮断により周囲に静脈灌流障害が生じるかなど, 術中に脳表の細動脈, 毛細血管, 細静脈の血流評価が求め られる状況が存在する。 そうした際に種々のモニタリング が用いられているが，いずれも有用性とともに限界も存在 する。超音波血流計 ${ }^{914)}$ は脳主幹動脈など径の太い血管に は使用しうるが, 脳表の毛細血管の血流評価は困難であ る. 組織血流計 ${ }^{17) 18}$ は脳表の血流量を絶対值として表示す るが, 計測ごとに測定值の変動が大きく信頼性の面で問題 がある. 電気生理学的モニタリング(2) 10111131 は神経機能を 評価する点で有用であるが，対象とする神経伝導路以外の 脳組織に関しては評価しえないＸ線を用いた術中脳血管 撮影(1)16) はカテーテル留置に伴う合併症のリスクや準備に 


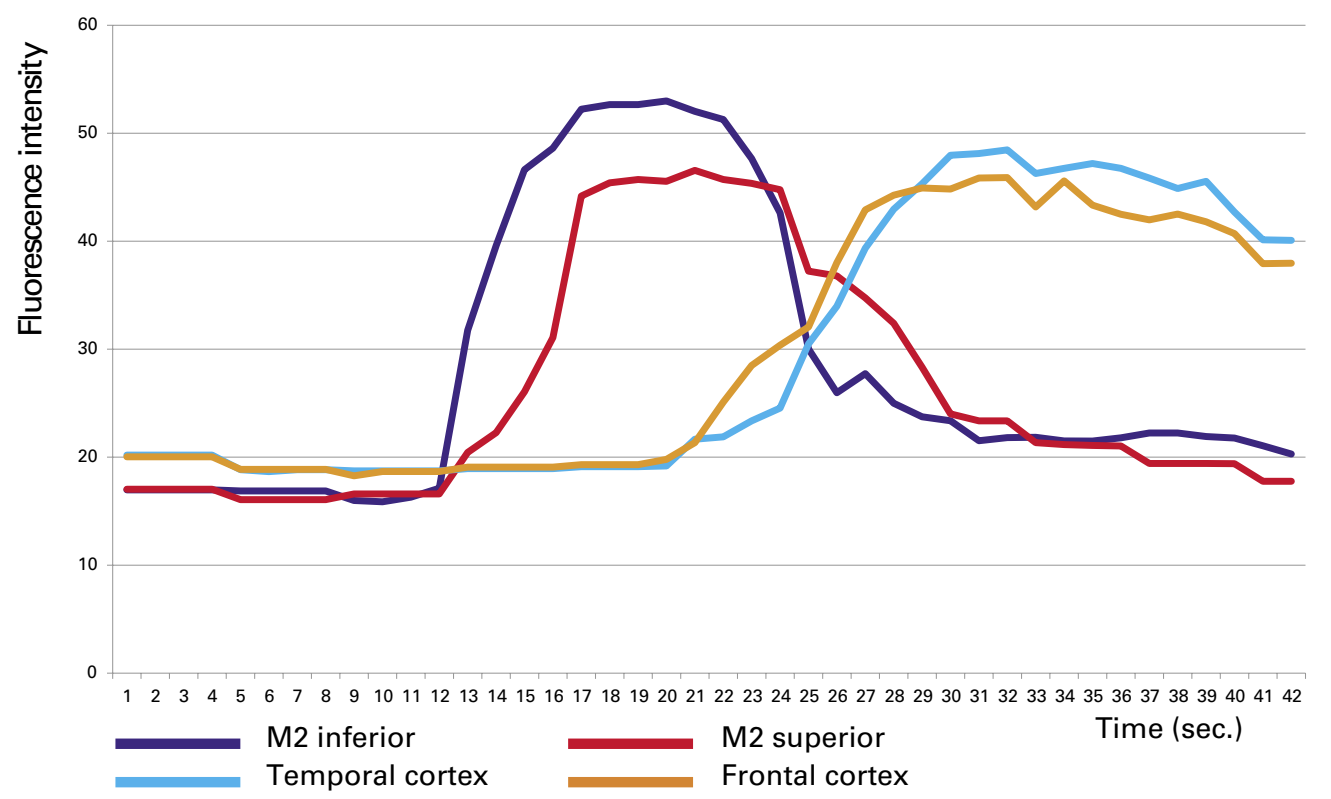

Fig. 4 Changes in fluorescence intensity at various ROls in the illustrative case 2. Graph of fluorescence intensity changes of fluorescein-FCAG suggested stenosis of superior trunk of $\mathrm{M} 2$, however, the graph of frontal cortex showed almost the same graph as temporal cortex.

要する労力の問題がある.

今回, 脳表の細動脈から毛細血管, 細静脈の血流評価を 目的とした modalityのひとつとして, FCAGの有用性と 問題点を検討した. ICG-FCAGで脳表の血流を評価し有 用であったとする報告 ${ }^{19)}$ はすでになされているが, fluoresein-FCAG を用いた脳表血流評価の報告は, われわれが 渉猟しえた限りこれまでみられていない. fluorescein と ICG の最大吸収波長/最大蛍光波長は, それぞれ 465-490/520-530 nm と 805/835 nm であり, 両色素によ る FCAG を連続して施行しても干渉し合うことはないこ とから, 今回の検討では同一症例において ICG-FCAG と fluorescein-FCAG とを連続して施行し, 両色素による脳 血管の描出能を検討した. その結果, fluorescein-FCAG は ICG-FCAGに比して壁の薄い血管の描出に優れ, 脳表 の細動脈や毛細血管, 静脈からの蛍光を明瞭に観察しえ た. 輝度解析ソフトによる評価では, ICG-FCAGにおい て動脈の輝度変化は明膫なピークとして示されたものの, 毛細血管や静脈で明瞭なピークが得られなかった。 今回使 用した解析ソフトは白色の輝度変化をグラフ化するため, 白色で描出される ICGに比して緑色で描出される fluorescein-FCAG では動脈相のピークが低值であったが, その 一方で毛細血管と静脈からの蛍光も明瞭であり, 輝度変化 を独立したピークとしてとらえることが可能であった．今 回の結果から, われわれは脳表の血流評価に関しては fluorescein-FCAG が有用と考えている.すずに報告されて
いるとおり ICG-FCAG は内頝動脈など壁の肥厚した血管 の描出に優れており ${ }^{15)}$, 両色素を使用目的に応じて使い分 けることが有用と思われた。

近年, 蛍光脳血管撮影の有用性に関する報告5-7)12) 15) 19220) が増えているが, そのほとんどは蛍光色素を静脈内投与 （静注 FCAG）している．静注 FCAG では血流の存在を確 認することは可能であるが, 血流動態の評価にはいくつか の問題点がある。ひとつは, 静注 FCAG では 1 回の検査 で投与する蛍光色素量が多いため 5-6 分後も血管内に色素 が残存し, 蛍光の洗い出しという面での評価が不可能なこ とである.このため静脈灌流障害の有無を静注 FCAG で 評価することは困難である，もうひとつの問題は, 静脈内 に投与された蛍光色素は脳動脈に到達するまでに cardiopulmonary circulation を介して希釈されるため, 脳血管 内に達した段階ではすでに蛍光色素濃度は低下し, 蛍光輝 度上昇が緩徐となることである，到達時間の遅延を評価す る際には, bolus injection された高濃度の蛍光色素塊を観 察する必要がある。

こうした静注 FCAGの問題点を解決するために, 動注 FCAGも施行され，その有用性が報告されている ${ }^{344}$. 動 注 FCAGには, digital subtraction angiography と同様 に鼠径部や前腕部より刺入したカテーテルを頝動脈あるい は大血管内に留置して蛍光色素を投与する方法と, 浅側頭 動脈に挿入したカテーテルから蛍光色素を注入する方法が 報告されている．前者はきわめて少量の蛍光色素により明 
瞭な蛍光画像が得られるが4), その一方でカテーテル留置 による合併症発生のリスクは無視できない. 後者はカテー テル留置に伴うリスクを軽減しうる方法であり, すでに臨 床応用され有用性が報告されている ${ }^{3)}$. 浅側頭動脈から注 入された蛍光色素は, 外澒動脈と内澒動脈との anastomosis を介した経路や, 外澒動脈内を逆流し頝動脈分岐部を 介する経路で内頝動脈に流入すると考えられる. 蛍光色素 は希釈されても強い輝度の蛍光を発することから, 今回の 希釈率と投与量でも十分な蛍光が観察された. 浅側頭動脈 から挿入したカテーテルをより総䅡動脈近くに進めればさ らに少ない投与量で明瞭な蛍光画像が得られると思われる が，多くの症例において浅側頭動脈は煩骨弓レベルで強く 屈曲蛇行しており, この部位を越えて総頝動脈側にカテー テルを進めることは困難であった.

浅側頭動脈から蛍光色素を注入する本手法では外頚動脈 系へ流れる色素も多く, 内澒動脈系へ流入する蛍光色素の 絶対量が把握できないことを認識しておく必要がある. 現 時点では測定しえない脳血流量の絶対值が評価可能な時代 となれば, 内頝動脈内にカテーテルを留置して一定量の蛍 光色素を投与することが求められるかもしれない. しか し, FAGでの血流評価が相対的なものにとどまっている 現時点では, 安全性と簡便性の点から浅側頭動脈を経由し た FCAG は有用な手法と考えている.

ICG-FCAG と fluorescein-FCAG におけるそれぞれの蛍 光色素投与量は, 動脈からの蛍光が明瞭でかつ静脈相以前 に消退することを目安として設定した. 蛍光の明瞭度は血 管内の蛍光色素濃度と励起光の光量に影響される. 今回の fluorescein-FCAG で使用した励起光量は, 技術的な問題 から ICG-FCAGの励起光量に比較して低いため, ICG-

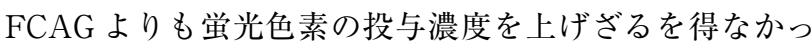
た. 今後より強い励起光を照射することが可能となれば, より低濃度の fluorescein 投与でも検査可能と思われる.

ICG においては, 顕微鏡に内蔵された血流の解析機能 (Flow 800, Carl Zeiss)により客観的な血流評価がなされ, 微妙な血流変化も可視化されるようになっている. fluorescein-FCAG では専用の血流解析ソフトが製品化されて いないため, 今回は市販されている沉用の輝度解析ソフト を使用したが, 動脈・毛細血管・静脈のいずれからも，そ れぞれ分離されたピークが形成された，各ピークの立ち上 がりと洗い出しはともに急峻であるため, 蛍光色素の到達 時間や洗い出しの遅延も評価可能であった。また，モ二 ター画面上に出現した蛍光が消失するまで, 静注法では 5 分以上を要したのに対して, 動注法では 1 分程度で消失す ることから，ほぼ 1 分間隔での検査の繰り返しが可能で あった. 本血流解析の問題点のひとつは, FCAG 施行後 に解析結果を得るまで 5 分程度の時間を要することであ
る. 穿通枝の血流途絶では短時間で不可逆的な虚血に陷る 可能性があることから, よりリアルタイムに血流評価を行 うことが今後の課題である.

\section{結 語}

動注 fluorescein-FAG は, 細動脈から毛細血管および静 脈の血流を明瞭に描出しうることから，脳表レベルでの血 流を評価するうえで有用であると思われた．輝度解析ソフ トを利用することで，血流遅延や血流停滞を探知すること が可能であった．しかし血流の絶対值を判断することは不 可能であり, 脳血流不全による術後合併症を予防するため には，脳電気生理学的検査など種々のモニタリングを併用 せざるを得ないのが現状である.

\section{文献}

1) Chiang VL, Gailloud P, Murphy KJ, et al: Routine intraoperative angiography during aneurysm surgery. $J \mathrm{Neu}$ rosurg 96: 988-992, 2002

2) Horiuchi K, Suzuki K, Sasaki $\mathrm{T}$, et al: Intraoperative monitoring of blood flow insufficiency during surgery of middle cerebral artery aneurysms. J Neurosurg 103: 275-283, 2005

3) Ichikawa T, Suzuki K, Watanabe Y: Intra-arterial fluorescence angiography with injection of fluorescein sodium from the superior temporal artery during aneurysm surgery. Neurol Med Chir (Tokyo) (in press)

4) Kuroda K, Kinouchi $\mathrm{H}$, Kanemaru K, et al: Intra-arterial injection fluorescein videoangiography in aneurysm surgery. Neurosurgery 72: 141-150, 2013

5) Raabe A, Back J, Gerlach R, et al: Near-infrared indocyanine green video angiography: a new method for intraoperative assessment of vascular flow. Neurosurgery 52: 132-139, 2003

6) Raabe A, Nakaji P, Beck J, et al: Prospective evaluation of surgical microscope-integrated intraoperative nearinfrared indocyanine green videoangiography during aneurysm surgery. J Neurosurg 103: 982-989, 2005

7) Rey-Dios R, Cohen-Gadol AA: Technical principles and neurosurgical applications of fluorescein fluorescence using a microscope-integrated fluorescence module. Acta Neurochir 155: 701-706, 2013

8) Sakuma J, Suzuki K, Sasaki T, et al: Monitoring and preventing blood flow insufficiency due to clip rotation after the treatment of internal carotid artery aneurysms. J Neurosurg 100: 960-962, 2004

9) Stendel R, Pietila T, Al Hassan AA, et al: Intraoperative microvascular Doppler ultrasonography in cerebral aneurysm surgery. J Neurol Neurosurg Psychiatry 68: 29-35, 2000

10) Suzuki K, Kodama N, Sasaki $\mathrm{T}$, et al: Intraoperative monitoring of blood flow insufficiency in the anterior choroidal artery during aneurysm surgery. $J$ Neurosurg 98: 507-514, 2003

11) Suzuki K, Sasaki T, Kodama N: Large aneurysm of the internal carotid artery obliterated with seven fenestrated clips under intraoperative monitoring of anterior cho- 
roidal arterial blood flow insufficiency, in Kobayashi S, Sakai K (eds): Neurosurgery of complex vascular lesions and tumors. New York: Thieme, 2005, pp42-46

12) Suzuki K, Kodama N, Sasaki $T$, et al: Confirmation of blood flow in perforating arteries using fluorescein cerebral angiography during aneurysm surgery. $J$ Neurosurg 107: 68-73, 2007

13）鈴木恭一, 佐々木達也, 松本正人, ほか: 運動誘発電位モ ニタリングを用いた脳動脈瘤手術. 脳卒中の外科 34: 101108,2006

14）鈴木恭一, 渡部洋一, 安藤 等, ほか：蛍光血管撮影と連 続的ドップラー血流検査を用いた脳動脈瘤手術における穿 通枝血流不全のモニタリング。脳卒中の外科 36: 427-433, 2008

15）鈴木恭一, 渡部洋一, 市川 剛：Fluorescein sodium を用 いた術中蛍光脳血管撮影による脳血流の評価. 脳卒中の外 科 37: $240-245,2009$
16) Tang G, Cawley CM, Dion JE, et al: Intraoperative angiography during aneurysm surgery: a prospective evaluation of efficacy. $J$ Neurosurg 96: 993-999, 2002

17）渡部洋一, 宗田 庸, 渡辺善一郎, ほか：Peltier 熱勾配式 組織血流計による術中血流モニタリング．東北脳血管障害 懇話会学術集会記録集 9:73-80, 1987

18）渡部洋一, 佐藤正憲, 後藤 健, ほか：脳動脈手術時の血 流一時遮断の有用性と問題点. 脳卒中の外科 19: 549-554, 1991

19) Woitzik J, Pena-Tapia PG, Schneider UC, et al: Cortical perfusion measurement by indocyanine-green videoangiography in patients undergoing hemicraniectomy for malignant stroke. Stroke 37: 1549-1551, 2006

20) Wrobel CJ, Meltzer H, Lamond $\mathrm{R}$, et al: Intraoperative assessment of aneurysm clip placement by intravenous fluorescein angiography. Neurosurgery 35: 970-973, 1994 